\title{
Nutrients, via the Tor proteins, stimulate the association of Tap42 with type 2A phosphatases
}

\author{
Charles J. Di Como ${ }^{1-3}$ and Kim T. Arndt ${ }^{1,4}$ \\ ${ }^{1}$ Cold Spring Harbor Laboratory, Cold Spring Harbor, New York 11724 USA; ${ }^{2}$ Graduate Program in Genetics, State \\ University of New York at Stony Brook, Stony Brook, New York 11794 USA
}

\begin{abstract}
We identified an essential Saccharomyces cerevisiae protein, Tap42, that associates with Sit4, a type 2A-related protein phosphatase, and with the type $2 \mathrm{~A}$ phosphatase catalytic subunits. The association of Tap42 with the phosphatases does not require the previously identified phosphatase subunits. Genetic analysis suggests that Tap42 functions positively with both phosphatases. Mutations in TAP42 can confer almost complete rapamycin resistance. In addition, Tap42/Sit4 and Tap42/PP2A complex formation is regulated by nutrient growth signals and the rapamycin-sensitive Tor signaling pathway. These findings, combined with the defect in translation of the tap42-11 mutant at the nonpermissive temperature, suggest that Tap42, Sit4, and PP2A are components of the Tor signaling pathway.
\end{abstract}

[Key Words: Tap42; Sit4; PP2A; phosphatase; rapamycin; Tor1 ; Tor2]

Received May 3, 1996; revised version accepted June 12, 1996.

In Saccharomyces cerevisiae, very little is known about how nutrient growth signals are transduced into the events that commit cells to enter the cell cycle and divide. Rapamycin is a potent antifungal and immunosuppressive macrolide that arrests $S$. cerevisiae cells and certain mammalian cells in $\mathrm{G}_{1}$ (Schreiber 1991; Cardenas et al. 1994). In budding yeast, rapamycin inhibits the function of the Tor 1 and Tor 2 proteins, and dominant point mutations in either TOR1 or TOR2 can render a cell resistant to rapamycin (Heitman et al. 1991; Cafferkey et al. 1993; Kunz et al. 1993; Stan et al. 1994; Zheng et al. 1995). Tor 1 and Tor 2 are homologous proteins that have a region related to phosphatidylinositol (PI) kinases and to double-stranded DNA-dependent protein kinase (Kunz et al. 1993; Hartley et al. 1995). Cells lacking both TOR1 and TOR2 arrest with an unbudded phenotype, similar to rapamycin-treated cells (Kunz et al. 1993; Helliwell et al. 1994; Zheng et al. 1995). Recently, it was shown that the Tor signaling pathway is required for the initiation of translation (Barbet et al. 1996), and these investigators suggested that this signaling pathway may regulate translation initiation in response to nutrient growth signals. Besides the Tor proteins, however, no other components of this important signal transduction pathway are currently known.

Many cell-cycle events are controlled by the regulation of the phosphorylation of certain cell-cycle sub-

\footnotetext{
${ }^{3}$ Present address: Department of Biological Sciences, Columbia University, New York, New York 10027 USA.

${ }^{4}$ Corresponding author.
}

strates. PP2A (type 2A) and Sit4 are two important classes of serine/threonine protein phosphatases (Arndt et al. 1989; Cohen 1989; Stark et al. 1994). The known forms of PP2A consist of a catalytic C-subunit bound to a regulatory A-subunit, and some forms have one of a number of regulatory B-subunits (Cohen 1989; Kamibayashi et al. 1991; Ruediger et al. 1991). The association of the AC form with a B-subunit might determine the substrate specificity of the PP2A enzyme. In S. cerevisiae, the C-subunit is encoded primarily by two genes, $P$ PH21 and $P$ PH22, which encode proteins that are $91 \%$ identical (Sneddon et al. 1990; Ronne et al. 1991; Sutton et al. 1991a). TPD3 encodes the 64-kD A-subunit, and CDC55 encodes a 60-kD B-subunit (Healy et al. 1991; van Zyl et al. 1992). In budding yeast, PP2A catalytic subunit activity is essential, whereas $\mathrm{Tpd} 3$ and $\mathrm{Cdc} 55$ are not essential (Healy et al. 1991; Ronne et al. 1991; van Zyl et al. 1992). PP2A activity has been implicated in the reorganization of the actin cytoskeleton, bud morphogenesis, and advancement from $G_{2}$ into mitosis (Ronne et al. 1991; Lin and Arndt 1995).

The SIT4 gene encodes the catalytic subunit of a type 2A-related phosphatase (Arndt et al. 1989). The function of Sit4 is distinct from that of PP2A. Sit4 is required during $G_{1}$ for the execution of Start, for bud formation, for the initiation of DNA synthesis, and for spindle pole body duplication (Arndt et al. 1989; Sutton et al. 1991a). Sit 4 is required for the execution of Start because it is required for the expression of the CLN1,CLN2, and PCL1 $\mathrm{G}_{1}$ cyclin genes (Fernandez-Sarabia et al. 1992). The $G_{1}$ cyclins bind to various cyclin-dependent kinases 
(CDKs), thereby activating the kinase activity (Richardson et al. 1989; Cross 1990; Tyers et al. 1992). When some threshold level of $\mathrm{G}_{1}$ cyclin/CDK kinase activity is achieved, Start is executed and the cells are committed for DNA synthesis and entry into the cell-cycle. If $\mathrm{Cln} 2$ is provided from a Sit4-independent promoter, temperature-sensitive sit4-102 cells arrest with replicated DNA but are still mostly blocked for bud initiation (Fernandez-Sarabia et al. 1992). Therefore, in addition to $G_{1}$ cyclin expression, Sit4 is also required in late $G_{1}$ for bud formation. The major Sit4-associated proteins are the high molecular mass Sap155, Sap185, and Sap190 proteins, which associate with Sit4 in a cell cycle-dependent manner and function positively with Sit4 (Sutton et al. 1991a; Luke et al. 1996). The Sit4-associated proteins (Saps) are either effectors of Sit4 or positive regulatory subunits of Sit4 (Luke et al. 1996).

In this report we identify Tap 42 and show that it is an essential protein that associates both with Sit4 and with the catalytic subunits of PP2A. Tap42 provides a function that is distinct from the previously identified Sit4 and PP2A associated proteins. Tap42/Sit4 and Tap42/ PP2A complex formation is regulated by nutrient growth signals and requires the Tor-signaling pathway. This and other evidence suggests that Tap42 may be a component of the rapamycin-sensitive Tor-signaling pathway.

\section{Results}

Isolation of high copy number suppressors of a sit4-102 strain

To identify proteins that are substrates of Sit4, regulate Sit4, or can partially substitute for Sit4, we isolated high copy number suppressors of a temperature-sensitive sit4102 strain (Sutton et al. 1991a). In addition to SIT4 and SSD1-v (Sutton et al. 1991a), three additional genes were isolated (see Materials and methods). To determine whether any of the three suppressors encode proteins that associate with Sit4, we labeled cells with ${ }^{35} \mathrm{~S}$ that overexpressed Sit4:hemagglutinin epitope (HA) and contained one of the three suppressors or a control vector. When the cells contained suppressor 1 in high copy number, a $155-\mathrm{kD}$ protein was present at higher levels in the Sit4:HA immunoprecipitates (data not shown). Suppressor 1 was subsequently shown to be $S A P 155$, which encodes one of the three Sap proteins known to associate with Sit4 (Sutton et al. 1991a; Luke et al. 1996). Suppressor 2 was $P C L 1 / H C S 26$ which encodes a $\mathrm{G}_{1}$ cyclin that associates with the Pho85 CDK and functions for progression through $\mathrm{G}_{1}$ (Ogas et al. 1991; Espinoza et al. 1994). If Pcll associates with Sit4, it would not be apparent on the gel because Sit4:HA and Pcll have similar molecular masses. Suppression by $P C L 1$ requires $P H O 85$ because a sit4-102 pho854 strain was not suppressed (data not shown). Interestingly, overexpression (either gene in high copy number or expressed from the $A D H 1$ promoter) of Pcll, but not the $\mathrm{G}_{1}$ cyclin $\mathrm{Cln} 2$ that associates with Cdc28, suppressed the sit4-102 strain /data not shown). Therefore, an increase in the levels of the
Pcl1/Pho85 kinase, but not the $\mathrm{Cln} 2 / \mathrm{Cdc} 28$ kinase, can suppress the temperature-sensitive phenotype of a sit4102 strain. These findings indicate either that Pcll/ Pho85 kinases can phosphorylate substrates that $\mathrm{Cln} /$ $\mathrm{Cdc} 28$ kinases cannot or that $\mathrm{Cln} / \mathrm{Cdc} 28$ kinases are Sit4 dependent while Pcll/Pho85 kinases are not. When the cells contained suppressor 3 , a $42-\mathrm{kD}$ protein was present at higher levels in the Sit4:HA immunoprecipitates (data not shown). In this report we present an analysis of the $42-\mathrm{kD}$ protein, termed Tap42 (for reasons described below).

Tap42 has significant sequence identity to the murine $\alpha 4$ phosphoprotein

The DNA sequence of the TAP42 gene (see Materials and methods/ predicts a protein of $42 \mathrm{kD}$ that is $24 \%$ identical overall $(37 \%$ similar including conservative substitutions) to the murine $\alpha 4$ protein, which becomes phosphorylated in response to stimulation of the immunoglobulin receptor in B cells (Fig. 1; Inui et al. 1995). Whereas some of the $\alpha 4$ protein is believed to exist beneath or at the cell membrane (Inui et al. 1995), it is currently not known whether any Tap42 is associated with membranes $>80 \%$ of Tap 42 is extracted in soluble lysates with a nondetergent breaking buffer; data not shown).

\section{TAP42 encodes an essential protein}

A diploid yeast strain with one of its two TAP42 genes replaced by the TRP1 gene was constructed /see Materials and methods). When the TAP42/tap $42 \Delta 4$ diploid was sporulated and the tetrads dissected and germinated on YP-glucose plates, only two of the four spores per tetrad gave rise to colonies. All viable spores were $\operatorname{Trp}^{-}$, indi-

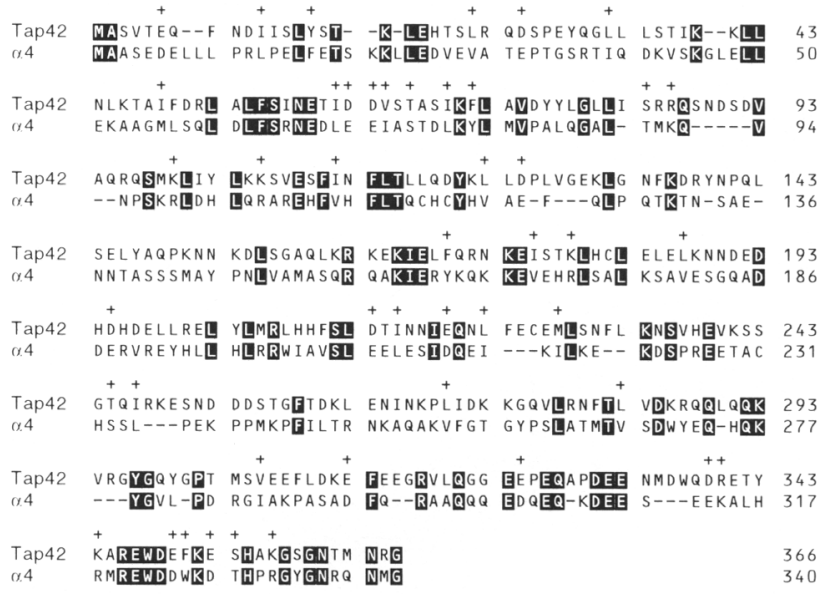

Figure 1. Tap42 is related to the murine $\alpha 4$ protein. The predicted Tap42 protein (GenBank accession no. U43890; $\mathrm{pI}=5.0$ ) and the murine $\alpha 4$ protein (Inui et al. 1995) were aligned using the GeneWorks program (IntelliGenetics, Inc). Identical amino acids are in reverse font and highly conserved amino acids are indicated with a + . 
cating that the inviable spores contained tap42 $44 . \mathrm{Mi}$ croscopic examination showed that the tap $42 \Delta 4$ spores germinated and completed one to three rounds (two to eight cells) of cell division, arresting uniformly as large unbudded cells. The inviability of tap $42 \Delta 4$ cells did not result from a defect during spore germination. Haploid tap $42 \Delta 4$ progeny containing the wild-type TAP42 gene on YCp50 cannot segregate viable cells that have lost the plasmid. These results show that TAP42 is essential.

Tap42 coprecipitates with Sit4 and the type $2 A$ phosphatases Pph21 and Pph22, but not the type 1 phosphatase Glc7

In budding yeast, PPH21 and PPH22 encode the two major catalytic subunits of type $2 \mathrm{~A}$ phosphatase (PP2A). At the nonpermissive temperature, temperature-sensitive pph21-102 or pph22-102 mutants arrest cell division with an altered bud morphology, a $2 \mathrm{~N}$ DNA content, and an undivided nucleus (Lin and Arndt 1995). High copy number TAP42 suppressed the temperature-sensitive phenotype of not only a sit4-102 strain, but also a pph21102 or a pph22-102 strain (data not shown). One model to explain this suppression is when TAP42, in interacting with Sit4, also associates with Pph21 and Pph22.

To test this possibility, cells containing either untagged or HA-tagged Sit4, Pph21, Pph22, and Glc7 (the type 1 phosphatase catalytic subunit; Feng et al. 1991) were grown to log phase and extracts were prepared. Sit4:HA, Pph21:HA, Pph22:HA, or Glc7:HA was precipitated with the anti-HA antibody, and Tap42 was detected on Western blots of the immunoprecipitates by use of anti-Tap42 antibodies. As expected from the experiments using ${ }^{35} \mathrm{~S}$-labeled extracts, Tap42 coprecipitated with Sit4:HA (Fig. 2, lane 2). Notably, Tap42 also coprecipitated both with Pph22:HA and with Pph21:HA (Fig. 2, lanes 4,6). Tap42 did not detectably coprecipitate with the type 1 phosphatase (Glc7:HA) and was not present in any of the untagged control lanes (Fig. 2, lane 8 and lanes 1,3,5, and 7, respectively). Additionally, Sap155 coprecipitated with Sit4:HA but not with the other phosphatase catalytic subunits (Fig. 2, lanes 2,4,6,8). Moreover, Tpd3 and Cdc55 coprecipitated with Pph21:HA and Pph22:HA but not at detectable levels with the other phosphatase catalytic subunits (Fig. 2, lanes $2,4,6,8)$. The amount of Tap42 protein was similar in the extracts as determined by Western analysis (Fig. 2, bottom, lanes 1-8). Because Tap42 associates with Sit4 and with Pph21 and Pph22 type 2A phosphatase catalytic subunits, we refer to this protein as Tap42 (for two $\mathrm{A}$ and related phosphatase-associated protein).

By Western analysis of extracts and serial dilutions of immunoprecipitates, we estimated that $<5 \%$ of Sit 4 and $<2 \%$ of Pph21 is stably associated with Tap42 (data not shown). Moreover, we estimated that $\sim 10 \%$ of Tap 42 is stably associated with Sit4:HA, 5\% with Pph21:HA, and 5\% with Pph22:HA. Because there is about five times more Pph21:HA or Pph22:HA in cells than Sit4:HA las measured using anti-HA antibodies|, Tap42 has a
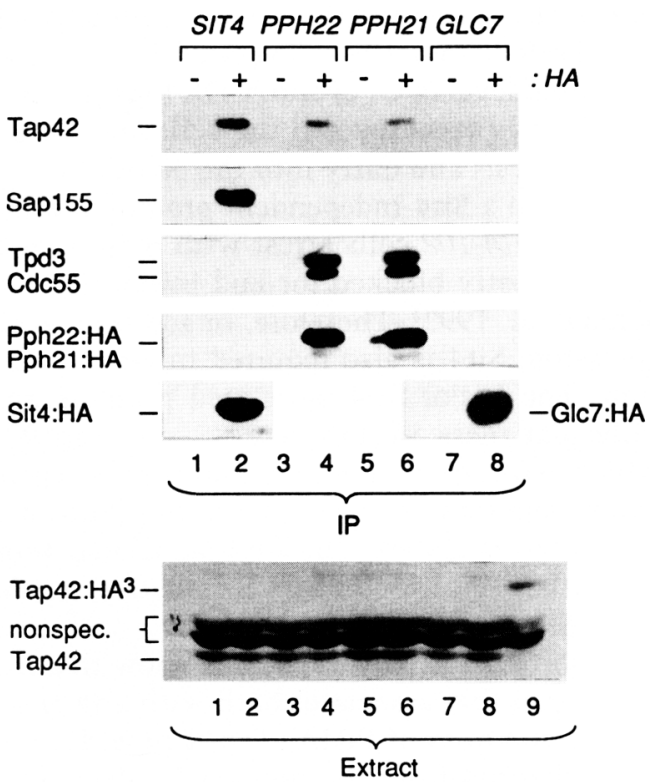

Figure 2. Tap42 coprecipitates with Sit4, Pph21, and Pph22, but not Glc7. Yeast strains were grown to log phase in YPglucose medium, and extracts were prepared. Immunoprecipitates of the extracts were electrophoresed on an SDS- $8 \%$ polyacrylamide gel. The relevant HA-tagged phosphatase precipitated with the anti-HA antibody is listed above each lane (IP) and the protein detected on the Western blot is listed to the left of each panel (for antibodies, see Materials and methods). $1+$ or - I The presence or absence, respectively, of the epitope tag on the phosphatase. For all immunoprecipitations, extract $15 \mathrm{mg}$ of protein) was incubated with $2 \mu \mathrm{l}$ of anti-HA ascites. (Lane 1) CY199 (SIT4); (lane 2) CY200 (SIT4:HA); (lane 3) CY1621 (PPH22); (lane 4) CY1622 (PPH22:HA); (lane 5) CY1623 (PPH21); (lane 6) CY1624 (PPH21:HA); (lane 7) CY969 (GLC7); (lane 8) CY971 (GLC7:HA). For Sit4:HA, Pph21:HA, Pph22:HA, and Glc7:HA, the blot was probed with anti-HA ascites. We show different exposure times for each phosphatase because the relative abundance of each differs in the cell /Glc7 is more abundant than Pph21 and Pph22, which are more abundant than Sit4). (Bottom) A Western blot analysis for lanes 1 to 8 plus lane 9 [CY4426 (TAP42:HA $\left.\left.{ }^{3}\right)\right]$ where $200 \mu \mathrm{g}$ of extract was loaded. (nonspec.) Nonspecific protein bands that migrate slower than Tap42 and cross-react with the anti-Tap42 antiserum.

slightly higher affinity for Sit4:HA than for Pph21:HA or Pph22:HA.

Tap42 can associate with Sit4 in the absence of Sap155, Sap185, and Sap190

In addition to Tap42, a novel family of proteins, Sap155, Sap185, and Sap190, associate with Sit4 (Sutton et al. 1991a; Luke et al. 1996). In extracts from asynchronous cells, $>50 \%$ of Sit 4 is associated with a Sap. Sap155 and Sap190 compete with each other for binding to Sit4, suggesting that they may bind to the same surface on Sit4 (Luke et al. 1996). The Saps might be required for Tap42 to associate with Sit4 or Tap42 could bind directly to the 
Saps. Alternatively, Tap42 may compete with the Saps for binding to Sit 4 and exist in an independent complex.

To test these possibilities, $5 \mathrm{mg}$ of extract containing Sap155:HA or Sap190:HA or $1 \mathrm{mg}$ of extract containing Sit4:HA was used for the immunoprecipitations. Tap42 coprecipitated with Sit4:HA (Fig. 3A, lane 5), but not at detectable levels with Sap155:HA or Sap190:HA (Fig. $3 \mathrm{~A}$, lanes 1,3 ). About $10 \%-20 \%$ of the Sap155 and Sap190 present in extracts is associated with Sit4:HA (Luke et al. 1996); therefore, Tap42 does not associate with the Saps that are not bound to Sit4. In addition, these findings suggest that Tap42 may not associate with Sap/Sit4 complexes.

In the extract from the wild-type strain, Tap42 and Sap155 associated with Sit4:HA (Fig. 3B, lane 2). Interestingly, the amount of Tap42 coprecipitating with Sit4:HA increased for the strain deleted for the SAP genes (Fig. 3B, lane 3), even though the amount of Tap42 protein in the extracts was similar (Fig. 3B, lanes 5,6). In summary, Tap42 does not require the Saps for binding to Sit4 and does not bind directly to Sap155 or Sap190.

Tap42 can associate with Pph21 in the absence of Tpd 3 and Cdc55

In budding yeast, the PP2A catalytic subunits associate with Tpd3 (A-subunit) and Cdc55 (B-subunit) (Healy et al. 1991; van Zyl et al. 1992). For mammalian PP2A, the A-subunit associates directly with the PP2A catalytic subunit (the $C$-subunit). In vitro studies have shown, however, that the B-subunit associates with the $\mathrm{AC}$ form and not the $\mathrm{C}$ form (Kamibayashi et al. 1991; Ruediger et al. 1991).

Therefore, Tap42 might require Tpd3 or Cdc55 to associate with Pph21 and Pph22. Alternatively, Tap42 may exist in a complex with Pph21 and Pph22 independent of Tpd3 and Cdc55. Tap42, Tpd3, and Cdc55 coprecipitated with Pph21:HA for the extract from the wild-type strain (Fig. 3C, lane 2). Interestingly, although the amount of Tap42 in the extracts was similar, more Tap42 coprecipitated with Pph21:HA for the tpd3s extract (lane 3) as compared with the wild-type extract (lane 2) even though there was less Pph21:HA in both the immunoprecipitate and the extract for the tpd3 $\Delta$ strain (Fig. $3 \mathrm{C}$ ). In addition, Cdc55 (a B-subunit) did not coprecipitate with Pph21:HA for the tpd3s extract (Fig. 3C, lane 3), similar to the results found in vitro in higher eukaryotes. In summary, Tap42 can associate with Pph 21 in the absence of Tpd3 and Cdc55.

\section{Tap42 combines with Pph2l or Sit4 to give a new} activity

Overexpression of Pph21 (pADH1:PPH21) causes a slow growth rate (F. Lin and K.T. Arndt, unpubl.). .pADH1: $P P H 21$ cells were transformed with a $p G A L 1$ expression plasmid containing either TAP42-coding sequences or no insert. The resulting strains grew at the same rate on YP-glucose plates, where Tap42 was not overexpressed (GAL1 promoter off; Fig. 4A). If Tap42 turns off Pph21, then overexpressing Tap42 along with Pph 21 should cure or partially cure the slow growth defect. However,

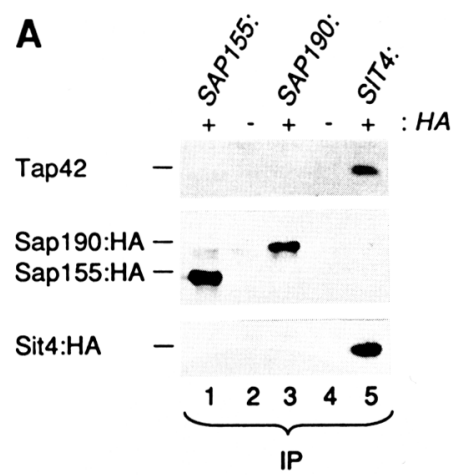

B

C

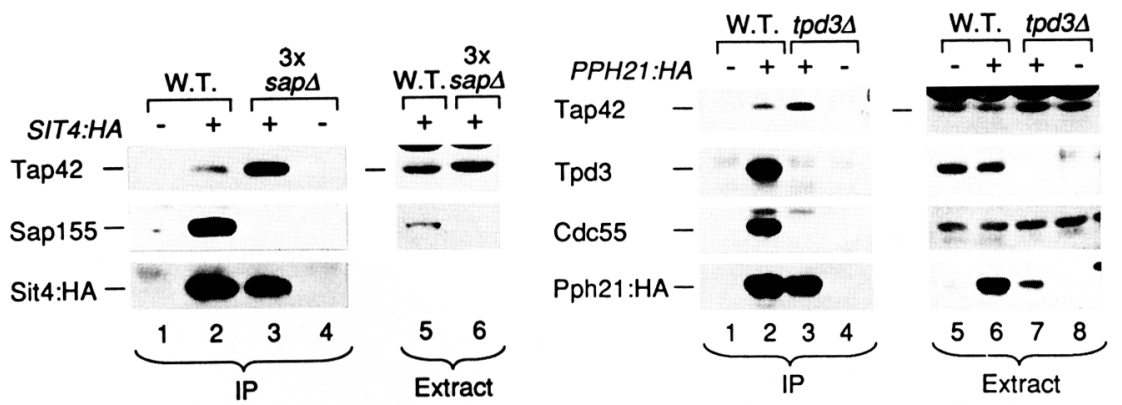

Figure 3. The Saps and the PP2A A and B subunits are not required for Tap $42 / S i t 4$ and Tap42/Pph 21 complex formation. Yeast strains were grown to log phase in SC minus uracil glucose media $(A, C)$ or in SC minus leucine glucose media $(B)$, and extracts were prepared. The relevant HA-tagged phosphatase or HA-tagged Sap immunoprecipitated with the anti-HA antibodies is listed above each lane (IP), and the protein detected on the Western blots is listed to the left of each panel (for antibodies, see Materials and methods). $1+$ or - I The presence or absence, respectively, of the epitope tag on the phosphatase or the Sap. For the immunoprecipitations in $A$, extract $(5 \mathrm{mg}$ of protein for lanes 1-3 and $1 \mathrm{mg}$ of protein for lanes 4 and 5) was incubated with $2 \mu \mathrm{l}$ of anti-HA antibody. For the Western blots (right panels) $150 \mu \mathrm{g}$ of extract was loaded. Because the levels of Sap155:HA and Sap190:HA are about five times greater than the levels of Sit4:HA in the immunoprecipitates, the exposure shown for Sap155:HA and Sap190:HA is much shorter than the exposure shown for Sit4:HA. Both SAP155:HA and SAP190:HA fully complement for their respective SAP function and the epitopetagged Saps interact normally with Sit4 (data not shown). For $B, 3 \mathrm{xsap} \Delta$ refers to the isogenic strain deleted for SAP155, SAP185, and SAP190. (A) (Lane 1) CY5391 (SAP155:HA); (lane 2) CY4800 (SAP190); (lane 3) CY4802 (SAP190:HA); (lane 4) CY199 (SIT4); (lane 5) CY200 (SIT4:HA). (B) (Lane 1) CY4776 (SIT4); (lanes 2,5) CY4777 (SIT4:HA); (lanes 3,6) CY5042 [sap1554 sap1854 sap1904

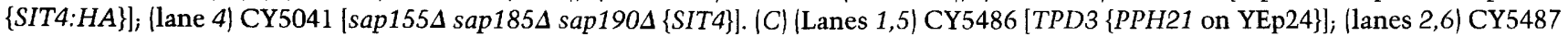
[TPD3 \{PPH21:HA on YEp24\}]; (lanes 3,7) CY5489 [tpd3A \{PPH21:HA on YEp24\}]; (lanes 4,8) CY5488 [tpd3A \{PPH21 on YEp24\}]. The tpd3A strains are isogenic to the TPD3 strains. 
when these cells were streaked onto YP-galactose plates (where Tap42 is overexpressed), those cells overexpressing both Pph 21 and Tap42 grew much more slowly than those overexpressing only Pph21 (Fig. 4A). Overexpression of Tap42 in the presence of wild-type levels of Pph2l had no effect on the growth rate of the cells (data not shown). Therefore, Tap42 and Pph21 together give an activity that is not provided either by Tap 42 alone or by Pph21 alone.

Cells overexpressing Sit4 (pADH1:SIT4) grow only slightly slower than wild-type cells (data not shown). pADH1:SIT4 cells were transformed with $p$ GAL1:TAP42 or the control plasmid. When these cells were streaked onto YP-galactose plates, those cells overexpressing both Sit 4 and Tap42 grew slower than the cells overexpressing only Sit4 (data not shown). Overexpression of Tap42 by itself had no effect on the growth rate of the cells (data not shown). These in vivo tests suggest that Tap42 functions positively with both Pph21 and Sit4.

\section{Alterations in Sit4 or Tap42 can give rapamycin resistance}

Because rapamycin arrests yeast cells in $G_{1}$ and temperature-sensitive sit 4 mutants arrest in $G_{1}$, we were interested in a possible connection between Sit 4 and the Torsignaling pathway that is inhibited by rapamycin. Cells overexpressing Sit 4 only, Pph21 only, or both Sit 4 and Pph21, all from the $A D H 1$ promoter, were tested for their ability to grow in the presence of rapamycin. Cells overexpressing Sit4 were weakly resistant to rapamycin (Fig. 4B). In contrast, cells overexpressing Pph21 were as sensitive to rapamycin as the control cells (Fig. 4B). Cells overexpressing both Sit4 and Pph21 were as weakly resistant to rapamycin as those overexpressing only Sit4 (Fig. 4B). Therefore, overexpression of Sit4, but not Pph21, gives weak rapamycin resistance.

Wild-type and isogenic tap42-11 mutants (see Materi- als and methods) were also tested for their ability to grow in the presence of rapamycin. Similar to the dominant TOR mutations that confer rapamycin resistance (Heitman et al. 1991; Cafferkey et al. 1993), the tap42-11 strain was almost completely resistant to rapamycin at the permissive temperature (Fig. 4C). At the nonpermissive temperature $\left(37^{\circ} \mathrm{C}\right)$, tap42-11 cells did not grow, whether or not rapamycin was present (data not shown). The tap42-11 strain was transformed with wild-type TAP42 on a URA3/CEN plasmid or the same plasmid without an insert. The tap42-11 \{TAP42\} cells were rapamycin resistant but not quite as resistant as the tap4211 \{vector\} cells (data not shown). Therefore, the tap4211 allele is semidominant for rapamycin resistance. In contrast, the tap42-11 allele is completely recessive to wild-type TAP42 for the temperature-sensitive phenotype. In addition, we have isolated two other rapamycinresistant alleles of TAP42 (data not shown). Therefore, similar to mutations in the TOR genes, mutations in the TAP42 gene can confer a rapamycin resistant phenotype and suggest that Tap42 and Sit4 may be components of the rapamycin-sensitive Tor-signaling pathway.

\section{Rapamycin dissociates Tap42 from Sit4 and Pph21}

Addition of rapamycin to exponentially growing cells rapidly caused the dissociation of Tap42 from Sit4:HA but had no effect on the association of Sap190 or Sapl55 with Sit4:HA (Fig. 5A, lanes 3-5). In addition, rapamycin rapidly caused the dissociation of Tap42 from Pph21:HA but had no effect on the association of Tpd3 or Cdc55 with Pph21:HA (Fig. 5A, lanes 6-8). Importantly, rapamycin did not affect the amount of Tap 42 protein in the extracts (Fig. 5A, lanes 1-10). Therefore, rapamycin does not decrease the levels of Tap42 but results in the dissociation of Tap42 from both Sit4 and Pph21.

To show that rapamycin can dissociate Tap42 from Sit4 at various stages of the cell-cycle, we arrested expo-
A

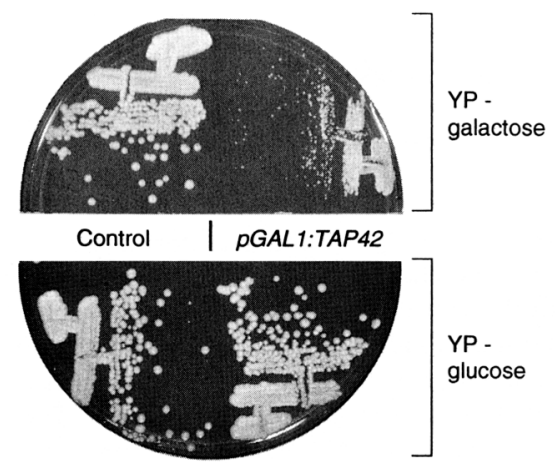

B

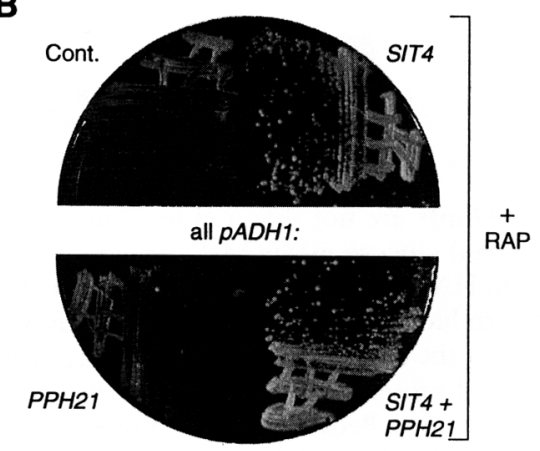

C

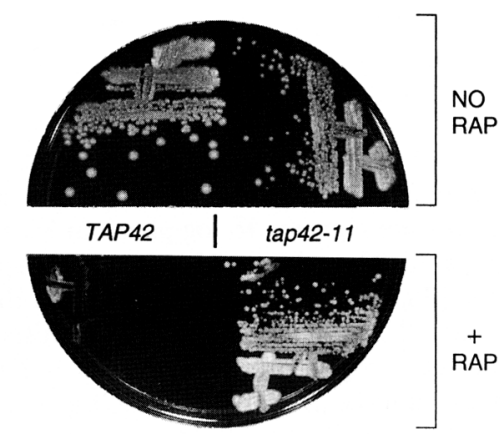

Figure 4. Effects due to the overexpression of Tap42, Sit4, and Pph21. (A) Strains CY5408 (pADH1:PPH21 plus $p$ GAL1 control) and CY5409 (pADH1:PPH21 plus $p$ GAL1:TAP42) were streaked onto either YP-glucose or YP-galactose plates and grown for 4 days at $30^{\circ} \mathrm{C}$. (B) Strains CY5628 (pADH1 control plus pADH1 control); CY5632 (pADH1 control plus pADH1:PPH21); CY5633 (pADH1:SIT4 plus $p A D H 1$ control); and CY5637 ( $p A D H 1$ :SIT4 plus $p A D H 1: P P H 21)$ were streaked from SC minus uracil minus leucine glucose plates onto YP-glucose plates containing either drug vehicle or rapamycin at $0.1 \mu \mathrm{g} / \mathrm{ml}(+\mathrm{RAP})$ and grown 5.5 days at $30^{\circ} \mathrm{C}$. $(C)$ Strains CY4907 (TAP42) and CY4908 (tap42-11) were streaked onto either YP-glucose plates containing drug vehicle (No RAP) or onto YP-glucose plates with rapamycin at $1.0 \mu \mathrm{g} / \mathrm{ml}$ ( $+\mathrm{RAP})$. The plates were grown for 4 days at $24^{\circ} \mathrm{C}$. 
A

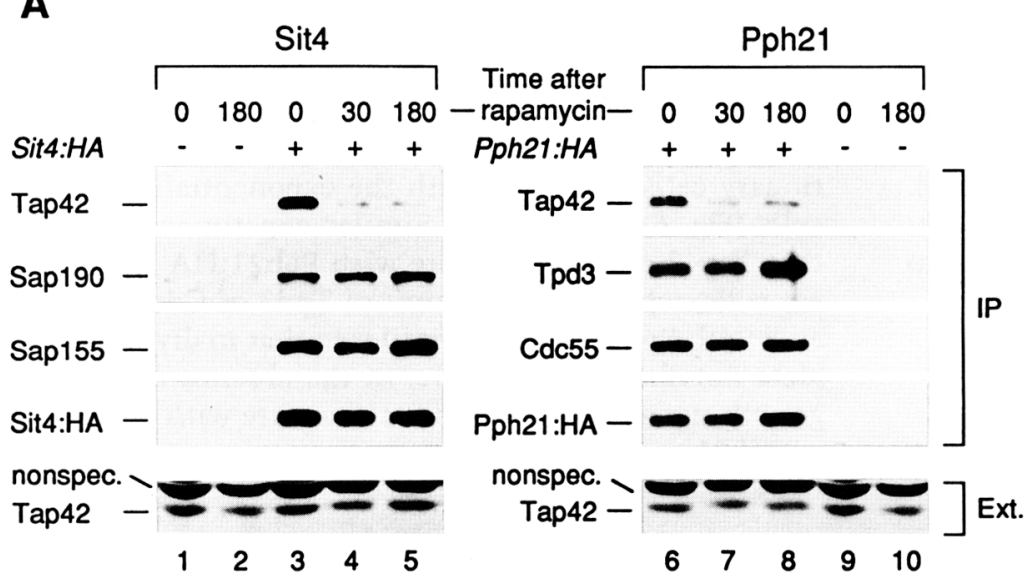

Figure 5. The association of Tap 42 with both Sit 4 and Pph 21 is sensitive to rapamycin and requires the Tor signaling pathway. Yeast strains were grown to $\log$ phase and extracts were prepared. Sit4:HA or Pph21:HA was precipitated from extracts (5 mg of protein) incubated with $2 \mu \mathrm{l}$ of anti$\mathrm{HA}$ ascites. Western blots of the immunoprecipitates (IP) were probed with antibodies listed in $\mathrm{Ma}$ terials and methods. The bottom panels (Ext.) are Western blot analyses, where $150 \mu \mathrm{g}$ of extract was loaded; (nonspec.) nonspecific protein bands that migrate slower than Tap42 and cross-react with the anti-Tap42 antiserum. (HU) Hydroxyurea-arrested cultures; (NOC) nocodazole-arrested cultures; $\left(T O R 2^{R}\right)$ dominant rapamycin-resistant $T O R 2^{S 1975 R}$ mutation. Rapamycin was added to a final concentration of $0.33 \mu \mathrm{g} / \mathrm{ml}$ for $A$ and $0.66 \mu \mathrm{g} / \mathrm{ml}$ for $B$. As determined by flow cytometry analysis, the hydroxyurea- and nocodazole-arrested cells maintained their respective cell-cycle arrests during the rapamycin treatment. Except for the TOR $2^{R}$ strain, which was grown in SC minus tryptophan glucose medium, all other strains were grown in YP-glucose medium. (A) (Lanes 1,2,9,10), CY199 (SIT4); llanes 3-5), CY200 (SIT4:HA); (lanes 6-8), CY1624 (PPH21:HA). (B) (Lanes 1-4), CY200 (SIT4:HA); (lanes 5,6), CY5607 [SIT4:HA $\left\{\right.$ TOR $2^{\text {S1975R }}$ on TRP1/CEN\}].

nentially growing cells in early $\mathrm{S}$ phase by the addition of hydroxyurea or in $M$ phase by the addition of nocodazole (arrests were confirmed by budding index and flow cytometry; data not shown). The arrested cells were subsequently treated with rapamycin or drug vehicle. Rapamycin caused the dissociation of Tap42 from Sit4:HA in cells arrested in early $S$ phase by hydroxyurea (Fig. 5B, lanes 1,2 ) and in cells arrested in $M$ phase by nocodazole (Fig. 5B, lanes 3,4). As expected, rapamycin had no effect on the Sap155/Sit4 complexes (Fig. 5B, lanes 1-4). The amount of Tap42 protein was similar for each extract, as determined by Western analysis (Fig. 5B, lanes 1-4). These results show that the dissociation of Tap42 from Sit4 by rapamycin is independent of cell-cycle position.

\section{A rapamycin-resistant TOR 2 mutation prevents dissociation of Tap42 from Sit4 by rapamycin}

Dominant point mutations in either TOR1 or TOR2 confer resistance to rapamycin, probably by reducing the affinity of the Tor proteins for the rapamycin/FKBP inhibitory complex (Heitman et al. 1991; Cafferkey et al. 1993). To test whether the effect of rapamycin on the association of Tap42 with Sit4 is via the Tor-signaling pathway, we took advantage of the dominant rapamycinresistant TOR2 $2^{S 1975 R}$ mutation (Freeman et al. 1996). Cells containing either HA-tagged or untagged Sit4 were transformed with the TOR2 or TOR2 $2^{S 1975 R}$ plasmids. In cells with the extra copy of wild-type TOR2, rapamycin still caused the dissociation of Tap42 from Sit4:HA /data not shown). In contrast, rapamycin did not cause the dissociation of Tap42 from Sit4:HA when the dominant rapamycin-resistant $T O R 2^{S 1975 R}$ mutation was present (Fig. 5B, lanes 5,6). The amount of Tap42 protein was similar for the extracts, as determined by Western analysis (Fig. 5B, lanes 5,6). Therefore, rapamycin causes the dissociation of Tap42 from Sit4 by inhibiting the Torsignaling pathway.

\section{Tap42 is not associated with Sit4 in cells starved} for nutrients

When yeast cells are limited for nutrients, they do not proceed through Start in late $G_{1}$ but, instead, exit the mitotic cell-cycle and enter stationary phase (WernerWashburne et al. 1993). Stationary phase is characterized by several physiological properties, including reduced protein synthesis, accumulation of glycogen, thermotolerance, resistance of the cell wall to digestion by Zymolyase, and alterations in patterns of transcription (Werner-Washburne et al. 1993). Loss of Tor function (rapamycin treatment or Tor depletion) causes yeast cells to arrest in a $\mathrm{G}_{1}$-like state with reduced protein synthesis and certain characteristics of stationary phase cells (Barbet et al. 1996).

We examined the association of Tap42 with Sit4 in 
stationary and exponential phase cells in four different culture media. In the dividing cells, Tap42 associated with Sit4:HA (Fig. 6A, lanes 1,3,5,7). Interestingly, the association of Tap42 with Sit4:HA was dramatically reduced when the cells were grown in medium with glycerol/ethanol, a poor carbon source (Fig. 6A, lane 5). Therefore, relative to glycerol/ethanol, glucose greatly stimulates Tap42/Sit 4 complex formation. In contrast to
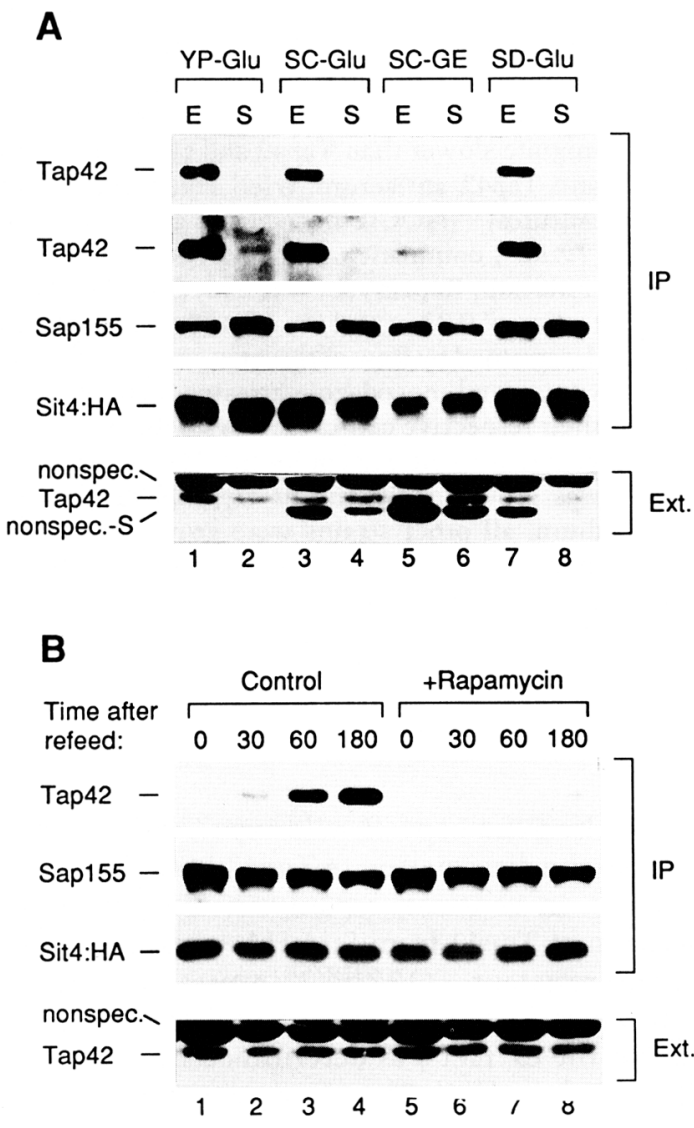

Figure 6. The association of Tap42 with Sit4 requires nutrient growth signals. Yeast strains were grown either exponentially or to stationary phase $\left(\mathrm{OD}_{600}>15\right)$ in the indicated media $(A)$ or YP-glucose $(B)$, and extracts were prepared. Sit4:HA was precipitated from extracts ( $5 \mathrm{mg}$ of protein) incubated with $2 \mu \mathrm{l}$ of anti-HA ascites. Western blots of the immunoprecipitates (IP) were probed with antibodies listed in Materials and methods. The bottom panels (Ext.) are Western blot analysis where $150 \mu \mathrm{g}$ of extract was loaded. (nonspec.) Nonspecific protein bands that migrate slower than Tap42 and cross-react with the anti-Tap42 antiserum; (nonspec.-S) nonspecific band that migrates faster than Tap42 and is induced by growth in SC or SD medium. (Glu) $2 \%$ glucose; (GE) $2 \%$ glycerol and $2 \%$ ethanol; (E) exponentially growing cells; and $(S)$ stationary cells. In $(B)$, stationary cells were given nutrient growth signals by dilution into fresh medium containing either drug vehicle or rapamycin at a final concentration of $0.66 \mu \mathrm{g} / \mathrm{ml}$. (A) (Lanes 1-8) CY200 (SIT4:HA). Two different exposures for Tap42 are shown. The Tap42 levels in the extracts are slightly variable. The lower levels of Tap 42 in the extract for lane 2 (YPD medium, stationary cells) are particular to this blot (e.g., see B). (B) (Lanes 1-8) CY200 (SIT4:HA). the exponentially growing cells, hardly any Tap42 associated with Sit4:HA in the stationary-phase cells (Fig. $6 \mathrm{~A}$, lanes $2,4,6,8$ ), even though Tap42 was present in the extracts (Fig. 6A, lanes 1-8). In contrast, Sap155/Sit4 complex formation was only slightly different in the stationary cells compared with the exponentially growing cells (Fig. 6A, lanes 1-8). Similar experiments showed that Tap42 did not associate with Pph21:HA in stationary cells, whereas the amount of $\mathrm{Tpd} 3$ or Cdc55 associated with Pph21:HA was similar to that in dividing cells (data not shown). Therefore, in the absence of nutrient growth signals, Tap42 does not associate with either Sit4 or Pph21.

When stationary phase cells are given nutrient growth signals, the Tor-signaling pathway is required for Tap42 to associate with Sit4 and Pph21

Giving nutrient growth signals to stationary-phase cells by dilution into fresh medium caused Tap42 to associate with Sit4:HA (Fig. 6B, lanes 1-4). In contrast, when stationary cells were diluted into fresh medium containing rapamycin, hardly any Tap42 associated with Sit4:HA (Fig. 6B, lanes 5-8) even though Tap42 was present in the extracts (Fig. 6B, lanes 1-8). Similar results and kinetics were obtained for Tap42/Pph21:HA complex formation upon refeeding stationary cells (data not shown). Upon refeeding, the association of Tap42 with both Sit4 and Pph21 slightly preceded progression into the mitotic cell cycle (as determined by flow cytometry and budding index; data not shown). Therefore, when stationary cells are given nutrient growth signals, the Tor-signaling pathway is required for Tap42 to associate with Sit4 and Pph2l.

At the nonpermissive temperature, tap42-11 cells have a defect in translation initiation

Rapamycin causes an unbudded arrest (Heitman et al. 1991). After $4 \mathrm{hr}$ at $37^{\circ} \mathrm{C}$, the temperature-sensitive tap42-11 strain (CY4908) arrested growth with $73 \%$ unbudded cells. In contrast, the isogenic TAP42 strain (CY4907) continued to divide during the $4 \mathrm{hr}$ at $37^{\circ} \mathrm{C}$ and had only $29 \%$ unbudded cells. Therefore, tap $42-11 \mathrm{mu}-$ tants arrest primarily as unbudded cells. Barbet et al. (1996) showed that addition of rapamycin to a wild-type strain or a defect in Tor function inhibited translation. If Tap42 functions in the Tor-signaling pathway, a defect in Tap42 should also result in the inhibition of translation. When a TAP42 strain was shifted to $37^{\circ} \mathrm{C}$, the polysome levels remained high (Fig. 7A). In contrast, the isogenic tap42-11 strain had slightly reduced levels of polysomes when grown at $24^{\circ} \mathrm{C}$ but had dramatically reduced levels of polysomes and a large increase in $80 \mathrm{~S}$ ribosomes when grown at $37^{\circ} \mathrm{C}$ (Fig. 7A). Addition of cycloheximide to the tap $42-11$ cells prior to the shift to $37^{\circ} \mathrm{C}$ completely prevented the loss of polysomes and prevented the increase in $80 \mathrm{~S}$ ribosomes (data not shown). Therefore, a defect in Tap42 results in a block in the initiation of translation. 
A
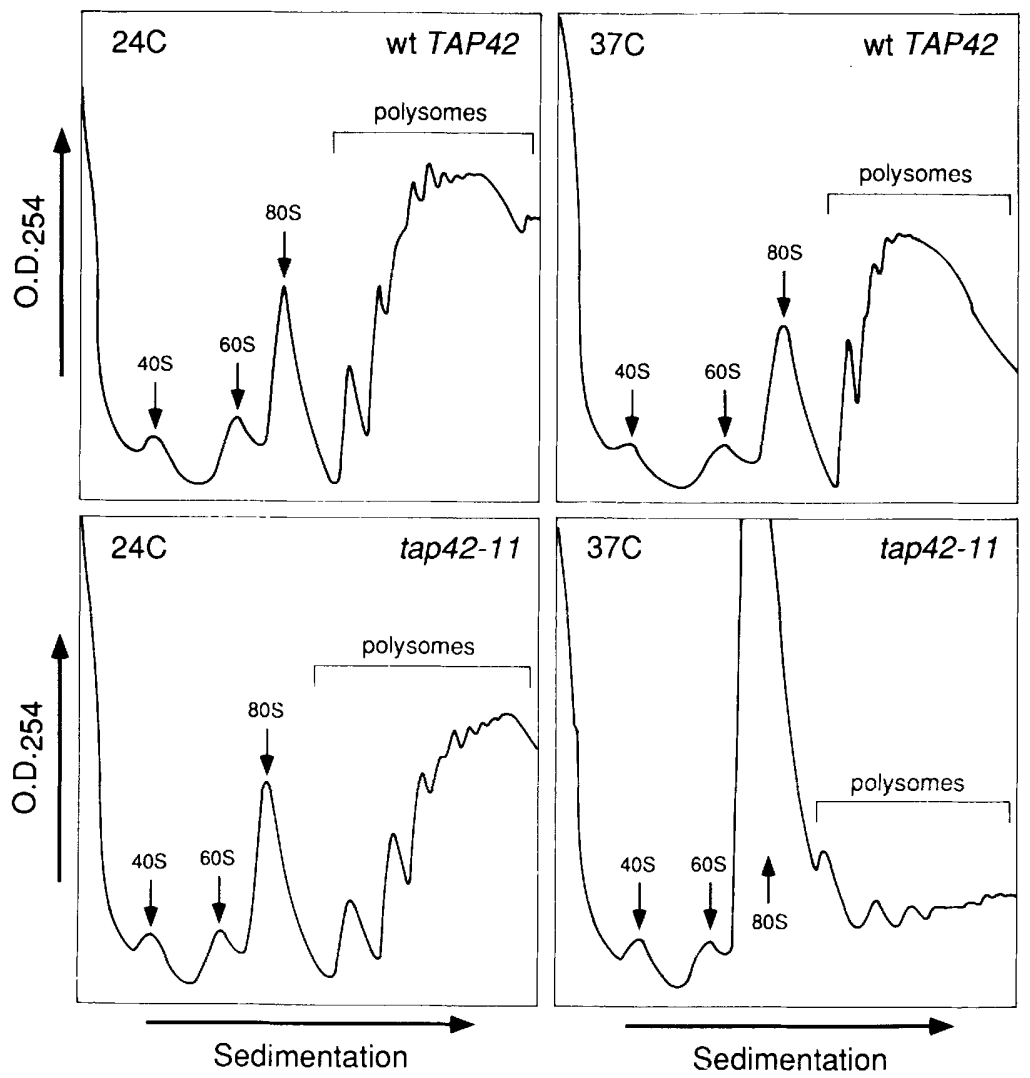

\section{B Model}

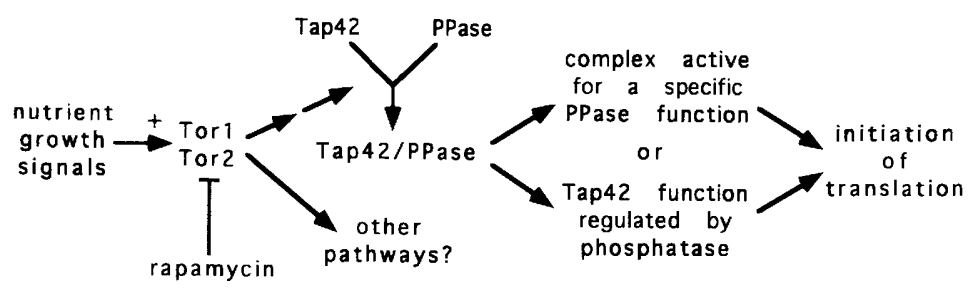

Figure 7. Tap42 is required for the initiation of translation. (A) TAP42 (CY4927) and isogenic tap42-11 (CY4928) cells, growing exponentially in YP-glucose medium at $24^{\circ} \mathrm{C}$, were shifted to $37^{\circ} \mathrm{C}$ for $4 \mathrm{hr}$. Five min prior to harvesting the cells, cycloheximide was added to $100 \mu \mathrm{g} / \mathrm{ml}$. Extracts were prepared and loaded onto sucrose gradients as described in Zhong and Arndt (1993). (B) Model of the Tor/Tap42 signal transduction pathway (for further details, see Discussion).

\section{Discussion}

Tap42 is a new type $2 A$ phosphatase-associated protein

PP2A catalytic activity in yeast is essential and is required for a normal actin cytoskeleton, bud morphogenesis, and the advancement from $\mathrm{G}_{2}$ into mitosis (Ronne et al. 1991; Lin and Arndt 1995). In contrast, Tpd3 (Asubunit) and Cdc55 (B-subunit) are not essential (Healy et al. 1991; van Zyl et al. 1992). Loss of Tpd3 reduces RNA polymerase III activity and causes a defect in cytokinesis, whereas loss of Cdc55 causes elongated buds and a partial block of septation (Healy et al. 1991; van Zyl et al. 1992). Sit4, a type 2A-related phosphatase catalytic subunit, is required in late $G_{1}$ for Start and for bud formation. Sit4 associates in a cell cycle-dependent manner with Sap155, Sap185, and Sap190 (Sutton et al. 1991a; Luke et al. 1996). The Saps function positively with Sit4, and the effects caused by the loss of Sap function are similar to the loss of Sit4 (Luke et al. 1996).

Our experiments show that Sit 4 and PP2A do not detectably share the previously identified subunits. The Saps are unique to Sit4, whereas $\mathrm{Tpd} 3$ and $\mathrm{Cdc55}$ are unique to PP2A. Nickels and Broach (1996) have suggested that the budding yeast ceramide-activated protein phosphatase is composed of regulatory subunits encoded by TPD 3 and CDC55 and a catalytic subunit encoded by SIT4. In their report, Nickels and Broach showed that Sit 4 and Tpd 3 cofractionated with the peak of ceramideactivated phosphatase activity over three columns, but they did not demonstrate that Sit4 physically associated with either Tpd3 or Cdc55. We have not been able to detect Tpd3 or Cdc55 in immunoprecipitates of Sit4. For these experiments, the immunoprecipitations were done in the presence or absence of ceramide, and Sit 4 was tagged with the HA epitope at the amino-terminal end or 
with the HA epitope or polyoma epitope at the carboxyterminal end (Fig. 2; data not shown). Although one could argue that the epitope tags on Sit 4 might reduce the association of Sit 4 with both Tpd3 and Cdc55, our failure to detect Tpd3 and Cdc55 in Sit4 immunoprecipitates raises the possibility that the peak of ceramideactivated protein phosphatase activity obtained by Nickels and Broach contained not only Sit 4 (which has a very weak phosphatase activity toward model substrates in vitrol but also Pph21 and Pph22 complexed with Tpd3 and Cdc55. Such PP2A complexes might give rise to the bulk of ceramide-activated protein phosphatase activity seen in vitro.

In this report we identify a new type $2 \mathrm{~A}$ phosphataseassociated protein, Tap42. Unlike Tpd3, Cdc55, and the Saps, Tap42 associates with both PP2A and Sit4. Tap42 is not a general protein phosphatase-associated protein because it is not present in type 1 phosphatase immunoprecipitates. We suggest that Tap42 provides a function distinct from the previously identified proteins that associate with Sit4 and PP2A.

The association of Tap42 with Sit4 and Pph21 does not require the previously identified phosphatase subunits

The Saps are not required for Tap $42 /$ Sit 4 complex formation. In addition, Tap42 does not detectably coprecipitate with Sap155:HA or Sap 190:HA. Moreover, overexpression of Sap155 or Sap190 does not compete with Tap42 for binding to Sit4 (data not shown). In contrast, in these same strains, Sap155 and Sap190 do compete with each other for binding to Sit4 (Luke et al. 1996), suggesting that there is a single Sap-binding site on Sit4. These findings, along with the lack of sequence similarity between Tap42 and the Saps, suggest that there is a binding site on Sit4 that specifies association with Tap42 and that this site is distinct from the Sap-binding site. Likewise, Tpd3 and Cdc55 are not required for the association of Tap42 with Pph21. In contrast, Cdc55 requires Tpd3 to associate with Pph21.

\section{Tap42 functions positively with both Sit4 and Pph21}

Our first line of evidence indicating that Tap42 functions positively with Sit4, Pph21, and Pph22 was that overexpression of Tap42 suppressed the temperaturesensitive phenotype of sit4-102, pph21-102, or pph22102 cells. The second line of evidence suggesting that Tap42 functions positively with both Sit4 and Pph21 was that overexpression of both Sit 4 and Tap 42 or both Pph21 and Tap42 resulted in a slower growth rate than overexpressing either Sit4 alone or Pph21 alone. If Tap42 was negatively regulating Sit 4 and $\mathrm{Pph} 21$, overexpression of Tap42 in cells overexpressing Sit4 or Pph21 should have had either no effect on the growth rate or should have partially cured the growth rate defect. Instead, the growth rate tests show that Tap42/Sit4 complexes and Tap $42 / \mathrm{Pph} 21$ complexes have an activity that is not provided by either Tap42 alone or the phosphatases alone.

\section{Alterations in Sit4 or Tap42 can confer rapamycin resistance}

Rapamycin inhibits the function of the TOR 1 and TOR2 proteins and arrests cells in $\mathrm{G}_{1}$ (Heitman et al. 1991; Cafferkey et al. 1993; Kunz et al. 1993; Stan et al. 1994; Zheng et al. 1995). A dominant point mutation in either TOR1 or TOR2 can render a cell resistant to rapamycin. Similarly, the tap42-11 allele also gives rapamycin resistance that is semidominant. This finding was the first indication that Tap 42 might be a component of the rapamycin-sensitive Tor signaling pathway. In addition, whereas overexpression of Sit 4 confers weak rapamycin resistance, overexpression of Pph21 does not confer rapamycin resistance. This finding suggests that Sit4 may also be a component, possibly as part of Tap $42 / S i t 4$ complexes, of the rapamycin-sensitive Tor signaling pathway.

\section{Significance of the similarity of Tap42 to $\alpha 4$}

Tap42 has significant sequence identity to the murine $\alpha 4$ protein, which is phosphorylated by the addition of phorbol esters or upon stimulation of the immunoglobulin- $\alpha$ receptor in B cells (Kuwahara et al. 1994; Inui et al. 1995). That nutrient growth signals, via the Tor proteins, stimulate the association of Tap42 with Sit4 and the catalytic subunits of PP2A raises the possibility that $\alpha 4$ may also be a component of a similar or equivalent signaling pathway. Possibly, $\alpha 4$ may associate with the mammalian type $2 \mathrm{~A}$ and type $2 \mathrm{~A}$-related phosphatases in response to stimulation of the immunoglobulin receptor or the addition of phorbol esters. Such a signal transduction pathway would be distinct from the type $2 \mathrm{~B}$ phosphatase pathway that is activated in response to increases in intracellular $\mathrm{Ca}^{2+}$ as a result of the phosphatidylinositol second messenger pathway (Liu et al. 1991; Gold et al. 1992).

The Tor pathway and nutrient growth signals are required for the association of Tap42 with the phosphatases

Rapamycin causes a rapid dissociation of Tap42 from both Sit4 and Pph21 while having no effect on the association of the Saps with Sit4 or the association of Tpd3 and Cdc55 with Pph21. Moreover, the dissociation of Tap42/Sit4 complexes by rapamycin is independent of cell-cycle position. In normal cycling cells, Tap42 may associate with the phosphatases at all stages of the cellcycle. In experiments where $c d c 15$ cells were synchronized in late mitosis by arresting at $37^{\circ} \mathrm{C}$, we could detect no changes in the relative levels of Tap42 coprecipitating with Sit4 at various times after shifting to $24^{\circ} \mathrm{C}$ (data not shown).

Importantly, rapamycin does not dissociate Tap42/ Sit 4 complexes in cells containing the dominant rapam- 
ycin-resistant $T O R 2^{S 1975 R}$ mutation. Therefore, a functional Tor-signaling pathway is required for Tap42 to associate with Sit4. In stationary cells, hardly any Tap 42 is associated with either Sit4 or Pph21, whereas the association of the Saps, Tpd3, and Cdc55 with these phosphatases is only slightly or not at all affected under these conditions. In addition, the association of Tap42 with both Sit4 and Pph21 is rapidly induced upon nutrient refeeding. In contrast, when stationary cells are released into fresh medium containing rapamycin, hardly any Tap42 associates with Sit4 or Pph21. These findings suggest that the Tor-dependent binding of Tap42 to Sit 4 and Pph21 is required for cells to enter the mitotic cell cycle.

Recently, it was shown that the addition of rapamycin or the loss of Tor function causes a defect in the initiation of translation and the induction of several characteristics (such as glycogen accumulation) of cells entering stationary phase (Barbet et al. 1996). These investigators suggested that the Tor-signaling pathway might sense and relay the availability of nutrients. In this report we have shown that like the Tor proteins, Tap42 is also required for the initiation of translation. Moreover, after $4 \mathrm{hr}$ at $37^{\circ} \mathrm{C}$, a temperature-sensitive tap $42-11 \mathrm{mu}^{-}$ tant acquires several of the characteristics of cells entering stationary phase, including the accumulation of high levels of glycogen and greatly increased resistance of the cell wall to digestion by Zymolyase (data not shown). Therefore, Tap42, possibly via Tor-dependent association with the Sit4, Pph21, and Pph22 phosphatases, might transmit nutrient growth signals to downstream processes such as the initiation of translation. In addition to the requirement of Tap42 for the initiation of translation, Tap42 may perform other functions that are required for cell-cycle progression.

\section{Functional significance of the association of Tap42 with both Sit4 and PP2A}

Temperature-sensitive sit4 mutants arrest in late $G_{1}$ (Sutton et al. 1991a), whereas temperature-sensitive pph21 or pph22 mutants arrest in $\mathrm{G}_{2}$ (Lin and Arndt 1995). These cell-cycle arrest phenotypes define the unique functions of the phosphatases. The late $G_{1}$ function of Sit4 is unique to the Sit4 phosphatase (PP2A cannot perform this function) and requires the interaction of Sit4 with the Sap proteins (Luke et al. 1996). Likewise, the $G_{2}$ function of PP2A is unique to Pph21/Pph22 and Sit4 cannot perform this function.

In contrast to sit 4 mutants or pph21 mutants, temperature-sensitive tap42-11 cells arrest primarily in a $\mathrm{G}_{1}$ like state with several characteristics of cells entering stationary phase. Possibly, Sit4 and Pph21/Pph22 have redundant roles for Tap42 function: A sit4-102 pph21102 double mutant (temperature-sensitive for both Sit4 and type $2 \mathrm{~A}$ phosphatases) arrests after $4 \mathrm{hr}$ at $37^{\circ} \mathrm{C}$ in a state that is very similar to that of arrested tap $42-11$ cells (primarily unbudded cells, high levels of glycogen, a cell wall highly resistant to digestion by Zymolyase, and a block in the initiation of translation; data not shown).
Neither sit4 nor pph21 single mutants arrest with all of these characteristics.

We envision the following model for the functional significance of the association of Tap 42 with both Sit4 and PP2A (Fig. 7B). Nutrient growth signals activate the Tor proteins; and the activated Tor proteins, possibly via intermediary factors or events, cause the association of Tap42 with Sit4, Pph21, and Pph22. For the regulated association of Tap42 with the phosphatases, which provide redundant functions with respect to Tap42, we propose two possibilities. First, Tap42 would function as a positive regulatory subunit for the phosphatases so that the Tap42/phosphatase complex is active for a specific phosphatase function. For the rapamycin-resistant tap42-11 mutant, Tap42-11 protein might be stably associated with the phosphatases and maintain a specific phosphatase activity that is insensitive to rapamycin. Second, Tap42 would be regulated by the phosphatases for a specific Tap42 function. For instance, the phosphatases might dephosphorylate Tap42, thereby regulating the ability of Tap42 to perform some function. In the case of the rapamycin-resistant tap42-11 mutant, the function of the Tap42-11 protein would be less dependent on the association with the phosphatases. Rapamycin, which inhibits the Tor-signaling pathway and prevents the association of wild-type Tap42 with the phosphatases, would either cause a reduction in the amount of Tap $42 /$ phosphatase-specific phosphatase activity or prevent the normal regulation of Tap42 function by the phosphatases. Whether or not the Tor-dependent association of Tap42 with the phosphatases is required for the translation initiation function of Tap42 remains to be determined. Future experiments will be directed at the elucidation of the role of the interaction of Tap42 with the phosphatases for cell-cycle progression and of the mechanism by which Tap42 is required for translation.

\section{Materials and methods}

Strains and growth conditions

Yeast strains are listed in Table l. Rich (YP), synthetic complete (SC), and minimal (SD) media are as in Luke et al. (1996). Carbon sources were at $2 \% \mathrm{wt}$./vol. final. For plasmid selection, the appropriate amino acid or uracil was omitted.

\section{Isolation of high copy number suppressors}

A sit4-102 strain (CY2813) was transformed with a high copy number library of yeast genomic DNA inserts in YEp24 (Carlson and Botstein 1982). After 4 days at $24^{\circ} \mathrm{C}$, the transformants $(60,000)$ were replica plated onto YP-glucose plates and incubated at $37^{\circ} \mathrm{C}$ and $38^{\circ} \mathrm{C}$ for $1-2$ days. Of the initial 1000 temperature-sensitive ${ }^{+}\left(\mathrm{Ts}^{+}\right)$transformants, 100 retested with a reproducible $\mathrm{Ts}^{+}$phenotype. For 40 of the $100 \mathrm{Ts}^{+}$transformants, $\mathrm{Ura}^{-}$segregants that lost the library plasmid gave back the original $\mathrm{Ts}^{-}$phenotype. The library plasmids were recovered from these 40 transformants. Of these, 34 contained the SIT4 gene and 1 contained SSD1-V (Sutton et al. 1991a). For the other five plasmids, one contained SAP155, one contained PCL1/HCS26, and three contained TAP42. 
Table 1. Strain list

\begin{tabular}{|c|c|}
\hline Strain & Relevant genotype \\
\hline CY199 & MATa sit4A::HIS3 ssd1-d2 \{SIT4 on LEU2/CEN\} W303 \\
\hline CY200 & MATa sit4A::HIS3 ssd1-d2 \{SIT4:HA on LEU2/CEN\} W303 \\
\hline CY969 & MATa $g l c 7 \Delta:: L E U 2$ ssd1-d2 $\{G L C 7$ on YCp50\} W303 \\
\hline CY971 & MATa $g l c 7 \Delta:: L E U 2$ ssd1-d2 $\{G L C 7: H A$ onYCp50\} W303 \\
\hline CY1621 & 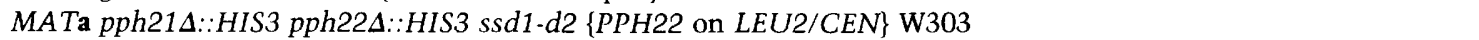 \\
\hline CY1622 & MATa pph21A::HIS3 pph22A::HIS3 ssd1-d2 $\{$ PPH22:HA on LEU2/CEN\} W303 \\
\hline CY1623 & MATa pph21A::HIS3 pph22A::HIS3 ssd1-d2 \{PPH21 on LEU2/CEN\} W303 \\
\hline CY1624 & MATa pph21A::HIS3 pph22A::HIS3 ssd1-d2 $\{$ PPH21:HA on LEU2/CEN\} W303 \\
\hline CY2813 & MATa sit4A::HIS3 ssd1-d1 \{sit4-102 on LEU2/CEN\} $\{T R P 1 / C E N\}$ \\
\hline CY4391 & MATa tap42A::TRP1 SSD1-V $\{T A P 42$ on LEU2/CEN\} W303 \\
\hline CY4426 & MATa tap42A::TRP1 SSD1-V $\left\{T A P 42: H A^{3}\right.$ on LEU2/CEN\} W303 \\
\hline CY4776 & MATa sit4A::HIS3 SSD1-V $\{S I T 4$ on LEU2/CEN\} $\mathrm{w} 303$ \\
\hline CY4777 & MATa sit4A::HIS3 SSD1-V $\{$ SIT4:HA on LEU2/CEN\} W303 \\
\hline CY4800 & MATa sap190A::TRP1 SSD1-V $\{S A P 190$ on YCp50\} W303 \\
\hline CY4802 & MATa sap190A::TRP1 SSD1-V $\{$ SAP190:HA on YCp50\} W303 \\
\hline CY4907 & MATa tap42A::TRP1 SSD1-V $\{T A P 42$ on $L E U 2 / C E N\}$ W303 \\
\hline CY4908 & MATa tap42A::TRP1 SSD1-V $\{$ tap42-11 on LEU2/CEN\} W303 \\
\hline CY4927 & MATa tap42A::HIS3 SSD1-v $\{$ TAP42 on LEU2/CEN\} W303 \\
\hline CY4928 & MATa tap42A::HIS3 SSD1-v $\{\operatorname{tap} 42-11$ on LEU2/CEN\} W303 \\
\hline CY5041 & MATa sit4A::HIS3 sap155A::HIS3 sap185A::ADE2 sap190A::TRP1 SSD1-V $\{$ SIT4 on LEU2/CEN\} W303 \\
\hline CY5042 & MATa sit4A ::HIS3 sap155A ::HIS3 sap185A::ADE2 sap190A::TRP1 SSD1-V $\{$ SIT4:HA on LEU2/CEN\} W303 \\
\hline CY5391 & MATa sap155A::HIS3 SSD1-V $\{$ SAP155:HA on YCp50\} W303 \\
\hline CY5408 & MATа pph21A::HIS3 pph22A::HIS3 ssd1-d2 $\{$ pADH1:PPH21 on $L E U 2 / 2 \mu\}\{p G A L 1$ on $U R A 3 / C E N\}$ W303 \\
\hline CY5409 & 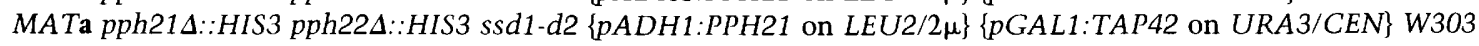 \\
\hline CY5486 & MATa TPD 3 PPH 21 on YEp24\} \\
\hline CY5487 & MATa TPD3 $\{P P H 21: H A$ on YEp24\} \\
\hline CY5488 & MATa $\operatorname{tpd} 3 \Delta:: L E U 2\{P P H 21$ on YEp24\} \\
\hline CY5489 & MATa tpd3A::LEU2 \{PPH21:HA onYEp24\} \\
\hline CY5607 & MATa sit4A::HIS3 ssd1-d2 $\left\{S I T 4: H A\right.$ on LEU2/CEN\} $\left\{T O R 2^{S 1975 R}\right.$ on TRP1/CEN\} W303 \\
\hline CY5628 & MATa SSD1-V $\{$ YEp24\}\{pADH1 on $L E U 2 / 2 \mu\}$ W303 \\
\hline CY5632 & MATa SSD1-V $\{$ YEp24\}\{pADH1:PPH21 on LEU2/2 $\mu\}$ W303 \\
\hline CY5633 & MATa SSD1-v $\{p A D H 1: S I T 4$ on YEp 24$\}\{p A D H 1$ on $L E U 2 / 2 \mu\}$ W303 \\
\hline CY5637 & MATa SSD1-V $\{p A D H 1: S I T 4$ on YEp 24$\}\{p A D H 1: P P H 21$ on $L E U 2 / 2 \mu\}$ W303 \\
\hline
\end{tabular}

The W303 (Thomas and Rothstein 1989) strains are ura3-1 leu2-3,-112 his3-11,-15 trp1-1 ade2-1 can1-100 and are isogenic except as indicated. CY199 and CY200 are from Sutton et al. (1991a), and CY969 and CY971 are from Sutton et al. (1991b). All other strains are from this study.

\section{DNA sequencing}

The TAP42 gene was localized on the original TAP42-containing library plasmids by subcloning restriction fragments into YEp24 and assaying for the ability to rescue the temperaturesensitive phenotype of sit4-102 mutants. A $1.8-\mathrm{kb}$ XbaI-BstEII subclone, in high copy number, contained full sit4-102 suppressor activity. This restriction fragment was cloned in both orientations into pUC119. Unidirectional nested deletion series were prepared, and the TAP42 gene was sequenced on both strands using Sequenase (U.S. Biochemical). This DNA sequence (GenBank accession no. U43890) contained one open reading frame that predicts a 366 amino acid protein. A frameshift mutation at the SalI site (codon 285) within the TAP42 open reading frame eliminated the sit4-102 suppressor activity.

\section{Deletion alleles of TAP42}

Oligonucleotide-directed mutagenesis (Kunkel 1985) was used to replace codons 2-361 of TAP42 (of 366 total codons) with a XhoI site. A $0.8-\mathrm{kb}$ EcoRI-Pst fragment containing the TRP1 gene (pCB2566; tap42 4 ) or a 1.8-kb BamHI fragment containing the HIS3 gene (pCB2564; tap4243) was placed into the XhoI site. tap $42 \Delta 3$ and tap $42 \Delta 4$ diploid transformants (the tap 42 de- letions were confirmed by Southern analysis) were sporulated and tetrads were dissected. In 40 tetrads for each diploid, no viable $\operatorname{Trp}^{+}$or His ${ }^{+}$haploid progeny were obtained. Haploid tap $42 \Delta 3$ or tap $42 \Delta 4$ strains containing the wild-type TAP42 gene on a plasmid could not grow in the absence of the plasmid.

Epitope-tagged Sit4, Glc7, Pph21, and Pph22

Sit4, epitope tagged at the amino terminus (Sit4:HA), is as described (Sutton et al. 1991a). Epitope-tagged Glc7 (Glc7:HA) is as described (Sutton et al. 1991b). For epitope-tagged Pph21 (Pph21:HA) and Pph22 (Pph22:HA), a duplex oligonucleotide encoding a single copy of the HA epitope was inserted in-frame between the second and third codons of either gene (F. Lin and K.T. Arndt, unpubl.).

\section{Expression of TAP42 from the GAL1 promoter}

A BamHI restriction site was created by oligonucleotide-directed mutagenesis (Kunkel 1985) 17 bp upstream of the predicted ATG initiation codon. Then, a $1.57-\mathrm{kb}$ BamHI restriction fragment containing the TAP42 open reading frame plus 447 bases of 3' sequence was cloned in the proper orientation into 
the BamHI site of a $p G A L 1 / U R A 3 / C E N$ expression plasmid (pAB486), yielding plasmid pCB2573. The pGAL1:TAP42 expression plasmid gave a wild-type growth rate to tap $42 \Delta 4$ cells when grown on YP-galactose medium, where $p G A L 1: T A P 42$ is expressed.

\section{Preparation of anti-Tap42 antibodies}

A 465-bp ScaI-AvaII fragment (135 codons) and a 325-bp AvaIIAvall fragment (108 codons) encoding different regions of Tap42 were inserted downstream of the malE gene in the pMAL-c2 vector (NEB), yielding plasmids pCB2620 and pCB2621, respectively. The Tap42 fusion proteins were expressed in Escherichia coli and purified on an $8 \%$ SDS-polyacrylamide gel. Crushed gel slices for the two fusion proteins were combined and used to raise polyclonal antibodies in rabbits (HRP, Inc.).

\section{Preparation of total protein extracts and Western immunoblots}

Cellular extracts and Western immunoblots were prepared as described (Sutton et al. 1991a), except for minor changes, including protein $\mathrm{G}$ beads (Pharmacia) being used for immunoprecipitation. For the Western blots, antibodies and their dilutions were polyclonal rabbit anti-Tap42 (1:2000); ascites fluid containing monoclonal anti-Sapl55 (1:10,000; Luke et al. 1996); polyclonal rabbit anti-Sap190 (1:1000, Luke et al. 1996); polyclonal rabbit anti-Tpd3 (1:2000; van Zyl et al. 1992); polyclonal rabbit anti-Cdc55 (1:2000; Healy et al. 1991); and ascites fluid containing monoclonal 12CA5 anti-HA $(1: 50,000$; Field et al. 1988). The proteins were visualized by Enhanced Chemiluminescence under conditions recommended by Amersham.

\section{Cell cycle synchronization}

For early S-phase arrest, cells were grown exponentially at $30^{\circ} \mathrm{C}$ in YP-glucose medium to an $\mathrm{OD}_{600}$ of 0.24 , and hydroxyurea powder (Fluka) was added to $0.2 \mathrm{M}$. After $3 \mathrm{hr}$ at $30^{\circ} \mathrm{C}$, which arrested the cells in early $\mathrm{S}$ phase as determined by flow cytometry, either drug vehicle $150 \%$ methanol $/ 50 \%$ dimethylsulfoxide) or rapamycin $(1 \mathrm{mg} / \mathrm{ml}$ in drug vehicle) was added. For $\mathrm{M}$-phase arrest, cells were grown exponentially at $30^{\circ} \mathrm{C}$ in YPglucose medium to an $\mathrm{OD}_{600}$ of 0.24 and nocodazole (Sigma; 15 $\mathrm{mg} / \mathrm{ml}$ in dimethylsulfoxide) was added to $15 \mu \mathrm{g} / \mathrm{ml}$. After $3 \mathrm{hr}$ at $30^{\circ} \mathrm{C}$, which arrested the cells in $\mathrm{M}$ phase as determined by flow cytometry, either drug vehicle or rapamycin $11 \mathrm{mg} / \mathrm{ml}$ in drug vehicle) was added.

\section{Isolation of tap42-11}

The TAP42 gene on a $L E U 2 / C E N$ plasmid (pCB2537) was mutagenized with hydroxylamine (Rose and Fink 1987) so that $5 \%$ did not complement for TAP42. Mutagenized plasmids were transformed into strain CY4391, which has a chromosomal deletion of TAP42 and the TAP42 gene on a URA3/CEN plasmid. $\mathrm{Leu}^{+}$transformants that had subsequently lost the URA3/CEN plasmid were selected on 5-fluoro-orotic acid (Boeke et al. 1984) and screened for a temperature-sensitive phenotype. From 22,000 transformants screened, we obtained one TAP42 plasmid (pCB2814) with a temperature-sensitive allele (tap42-11).

\section{Acknowledgments}

We especially thank G. Livi for the rapamycin and $T O R^{R}$ plasmids. We thank J. Broach, F. Della Seta, F. Lin, and M. Luke for yeast strains and plasmids, J. Broach for the anti-Tpd3 antibod- ies, J. Pringle for the anti-Cdc55 antibodies, P. Burfeind for flow cytometry, and J. Duffy and P. Renna for figure preparation and photography. Helpful comments on the manuscript were made by B. Futcher, F. Della Seta, and H. Ma. This research was funded by National Institutes of Health grant GM45179 and the Council for Tobacco Research grant 4173 to K.T.A.

The publication costs of this article were defrayed in part by payment of page charges. This article must therefore be hereby marked "advertisement" in accordance with 18 USC section 1734 solely to indicate this fact.

\section{References}

Arndt, K.T., C.A. Styles, and G.R. Fink. 1989. A suppressor of a HIS4 transcriptional defect encodes a protein with homology to the catalytic subunit of protein phosphatases. Cell 56: 527-537.

Barbet, N.C., U. Schneider, S.B. Helliwell, I. Stansfield, M.F. Tuite, and M.N. Hall. 1996. TOR controls translation initiation and early $\mathrm{G}_{1}$ progression in yeast. Mol. Biol. Cell 7: 2542.

Boeke, J.D., F. Lacroute, and G.R. Fink. 1984. A positive selection for mutants lacking orotidine- $5^{\prime}$-phosphate decarboxylase activity in yeast: 5-Fluoro-orotic acid resistance. Mol. \& Gen. Genet. 197: 345-346.

Cafferkey, R., P.R. Young, M.M. McLaughlin, D.J. Bergsma, Y. Koltin, G.M. Sathe, L. Faucette, W.K. Eng, R.K. Johnson, and G.P. Livi. 1993. Dominant missense mutations in a novel yeast protein related to mammalian phosphatidylinositol 3 -kinase and VPS34 abrogate rapamycin toxicity. Mol. Cell. Biol. 13: 6012-6023.

Cardenas, M.E., M. Lorenz, C. Hemenway, and J. Heitman. 1994. Yeast as model T cells. Perspect. Drug Discovery Design 2: 103-126.

Carlson, M. and D. Botstein. 1982. Two differentially regulated mRNAs with different $5^{\prime}$ ends encode secreted and intracellular forms of yeast invertase. Cell 28: 145-154.

Cohen, P. 1989. The structure and regulation of protein phosphatases. Annu. Rev. Biochem. 58: 485-497.

Cross, F.R. 1990. Cell cycle arrest caused by CLN gene deficiency in Saccharomyces cerevisiae resembles START-I arrest and is independent of the mating-pheromone signaling pathway. Mol. Cell. Biol. 10: 6482-6490.

Espinoza, F.H., J. Ogas, I. Herskowitz, and D.O. Morgan. 1994. Cell cycle control by a complex of the cyclin Hcs26 (Pcl1) and the kinase Pho85. Science 266: 1388-1391.

Feng, Z., S.E. Wilson, Z.Y. Peng, K.K. Schlender, E.M. Reiman, and R.J. Trumbly. 1991. The yeast GLC7 gene required for glycogen accumulation encodes a type 1 protein phosphatase. J. Biol. Chem. 266: 23796-23801.

Fernandez-Sarabia, M.J., A. Sutton, T. Zhong, and K.T. Arndt. 1992. Sit4 protein phosphatase is required for the normal accumulation of SWI4, CLN1, CLN2, and HCS26 RNAs during late $\mathrm{G}_{1}$. Genes \& Dev. 6: 2417-2428.

Field, J., J. Nikawa, D. Broek, B. MacDonald, L. Rogers, I.A. Wilson, R.A. Lerner, and M. Wigler. 1988. Purification of a RAS-responsive adenylyl cyclase complex from Saccharomyces cerevisiae by use of an epitope addition method. Mol. Cell. Biol. 8: 2159-2165.

Freeman, K. and G.P. Livi. 1996. Missense mutations at the FKBP12-rapamycin binding site of TOR1. Gene (in press).

Gold, M.R., V.W.-F. Chan, C.W. Turck, and A.L. DeFranco. 1992. Membrane Ig cross-linking regulates phosphatidylinositol 3-kinases in B lymphocytes. I. Immunol. 148: 20122022. 
Hartley, K.O., D. Gell, G.C.M. Smith, H. Zhang, N. Divecha, M.A. Connelly, A. Admon, S.P. Lees-Miller, C.W. Anderson, and S.P. Jackson. 1995. DNA-dependent protein kinase catalytic subunit: A relative of phosphatidylinositol 3-kinase and the ataxia telangiectasia gene product. Cell 82: 849-856.

Healy, A.M., S. Zolnierowicz, A.E. Stapleton, M. Goebl, R.A. DePaoli, and J.R. Pringle. 1991. CDC55, a Saccharomyces cerevisiae gene involved in cellular morphogenesis: Identification, characterization, and homology to the $\mathrm{B}$ subunit of mammalian type 2A protein phosphatase. Mol. Cell. Biol. 11: $5767-5780$

Heitman, J., N.R. Movva, and M.N. Hall. 1991. Targets for cellcycle arrest by the immunosuppressant rapamycin in yeast. Science 253: 905-909.

Helliwell, S.B., P. Wagner, J. Kunz, M. Deuter-Reinhard, R. Henriquez, and M.N. Hall. 1994. Tor 1 and Tor2 are structurally and functionally similar but not identical phosphatidylinositiol kinase homologs in yeast. Mol. Biol. Cell 5: 105-118.

Inui, S., K. Kuwahara, J. Mizutani, K. Maeda, T. Kawai, H. Nakayasu, and N. Sakaguchi. 1995. Molecular cloning of a cDNA clone encoding a phosphoprotein component related to the Ig receptor-mediated signal transduction. I. Immunol. 154: 2714-2723.

Kamibayashi, C., R. Estes, C. Slaughter, and M.C. Mumby. 1991. Subunit interactions control protein phosphatase $2 \mathrm{~A}$. J. Biol. Chem. 266: 13251-13260.

Kunkel, T.A. 1985. Rapid and efficient site-specific mutagenesis without phenotypic selection. Proc. Natl. Acad. Sci. 82: 488-492.

Kunz, J., R. Henriquez, U. Schneider, M. Deuter-Reinhard, N.R. Movva, and M.N. Hall. 1993. Target of rapamycin in yeast, Tor2, is an essential phosphatidylinositol kinase homolog required for $G_{1}$ progression. Cell 73: 585-596.

Kuwahara, K., T. Matsuo, J. Nomura, H. Igarashi, M. Kimoto, S. Inui, and N. Sakaguchi. 1994. Identification of a $52-\mathrm{kDa}$ molecule (p52) co-precipitated with the Ig receptor-related MB-1 protein that is inducibly phosphorylated by the stimulation with phorbol myristate acetate. I. Immunol. 152: 2742-2752.

Lin, F.C. and K.T. Arndt. 1995. The role of Saccharomyces cerevisiae type $2 \mathrm{~A}$ phosphatase in the actin cytoskeleton and in entry into mitosis. EMBO I. 14: 2745-2759.

Liu, J., J.D. Farmer Jr., W.S. Lane, J. Friedman, I. Weissman, and S.L. Schreiber. 1991. Calcineurin is a common target of cyclophilin-cyclosporin A and FKBP-FK506 complexes. Cell 66: $807-815$.

Luke, M.M., F. Della Seta, C.J. Di Como, R. Kobayashi, and K.T. Arndt. 1996. The SAPs, a new family of proteins, associate and function positively with the SIT4 phosphatase. Mol. Cell. Biol. 16: 2744-2755.

Nickels, J.T. and I.R. Broach 1996. A ceramide-activated protein phosphatase mediates ceramide-induced $\mathrm{G}_{1}$ arrest of Saccharomyces cerevisiae. Genes \& Dev. 10: 382-394.

Ogas, J., B.J. Andrews, and I. Herskowitz. 1991. Transcriptional activation of CLN1,CLN2, and a putative new $\mathrm{G}_{1}$ cyclin (HCS26) by SWI4, a positive regulator of $\mathrm{G}_{1}$-specific transcription. Cell 66: 1015-1026.

Richardson, H.E., C. Wittenberg, F. Cross, and S.I. Reed. 1989. An essential $G_{1}$ function for cyclin-like proteins in yeast. Cell 59: 1127-1133.

Ronne, H., M. Carlberg, G.-Z. Hu, and J.O. Nehlin. 1991. Protein phosphatase $2 \mathrm{~A}$ in $S$. cerevisiae: Effects on cell growth and bud morphogenesis. Mol. Cell. Biol. 11: 4876-4884.

Rose, M.D. and G.R. Fink. 1987. KAR1, a gene required for function of both intranuclear and extranuclear microtubules in yeast. Cell 48: 1047-1060.
Ruediger, R., J.E. Van Wart Hood, M. Mumby, and G. Walter. 1991. Constant expression and activity of protein phosphatase $2 \mathrm{~A}$ in synchronized cells. Mol. Cell. Biol. 11: 42824285.

Schreiber, S.L. 1991. Chemistry and biology of the immunophilins and their immunosuppressive ligands. Science 251: 283287.

Sneddon, A.A., P.T.W. Cohen, and M.J.R. Stark. 1990. Saccharomyces cerevisiae protein phosphatase $2 \mathrm{~A}$ performs an essential cellular function and is encoded by two genes. $E M B O$ I. 9: 4339-4346.

Stan, R., M.M. McLaughlin, R. Cafferkey, R.K. Johnson, M. Rosenberg, and G.P. Livi. 1994. Interaction between FKBP12-rapamycin and Tor involves a conserved serine residue. J. Biol. Chem. 269: 32027-32030.

Stark, M.J.R., S. Black, A.A. Sneddon, and P.D. Andrews. 1994. Genetic analysis of protein serine/threonine phosphatases. FEMS Microbiol. Lett. 117: 121-130.

Sutton, A., D. Immanuel, and K.T. Arndt. 1991a. The Sit4 protein phosphatase functions in late $G_{1}$ for progression into $S$ phase. Mol. Cell. Biol. 11: 2133-2148.

Sutton, A., F. Lin, M.J. Fernandez-Sarabia, and K.T. Arndt. $1991 \mathrm{~b}$. The Sit4 protein phosphatase is required in late $G_{1}$ for progression into S phase. Cold Spring Harbor Symp. Quant. Biol. 56: 75-81.

Thomas, B.J. and R. Rothstein. 1989. Elevated recombination rates in transcriptionally active DNA. Cell 56: 619-630.

Tyers, M., G. Tokiwa, R. Nash, and B. Futcher. 1992. The Cln3$\mathrm{Cdc} 28$ kinase complex of $S$. cerevisiae is regulated by proteolysis and phosphorylation. EMBO I. 11: 1773-1784.

van Zyl, W., W.D. Huang, A.A. Sneddon, M. Stark, S. Camier, M. Werner, C. Marck, A. Sentenac, and J.R. Broach. 1992. Inactivation of the protein phosphatase $2 \mathrm{~A}$ regulatory subunit A results in morphological and transcriptional defects in Saccharomyces cerevisiae. Mol. Cell. Biol. 12: 49464959.

Werner-Washbune, M., E. Braun, G.C. Johnston, and R.A. Singer. 1993. Stationary phase in the yeast Saccharomyces cerevisiae. MicroBiol. Rev. 57: 383-401.

Zheng, X.-F., D. Fiorentino, J. Chen, G.R. Crabtree, and S.L. Schreiber. 1995. Tor kinase domains are required for two distinct functions, only one of which is inhibited by rapamycin. Cell 82: 121-130.

Zhong, T. and K.T. Arndt. 1993. The yeast Sisl protein, a Dnal homolog, is required for the initiation of translation. Cell 73: $1175-1186$. 


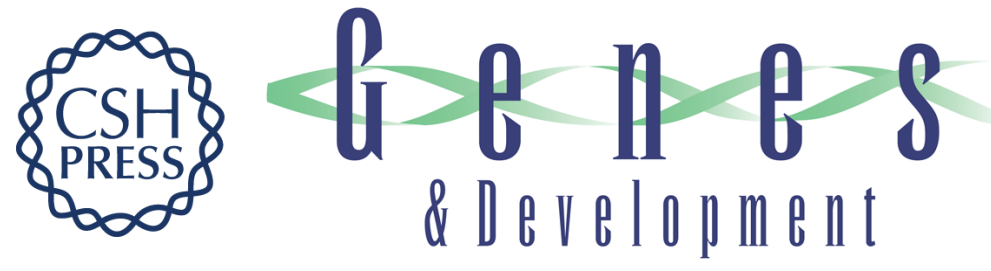

\section{Nutrients, via the Tor proteins, stimulate the association of Tap42 with type 2A phosphatases.}

C J Di Como and K T Arndt

Genes Dev. 1996, 10:

Access the most recent version at doi:10.1101/gad.10.15.1904

References This article cites 43 articles, 24 of which can be accessed free at:

http://genesdev.cshlp.org/content/10/15/1904.full.html\#ref-list-1

License

Email Alerting

Service

Receive free email alerts when new articles cite this article - sign up in the box at the top right corner of the article or click here.

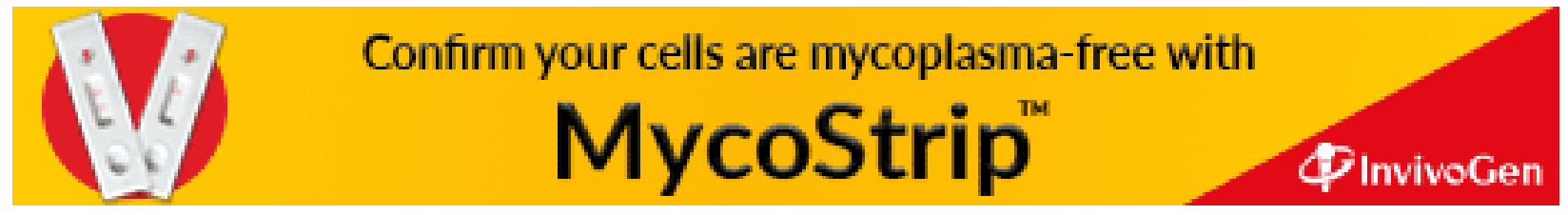

